\title{
CD38 expression as response of hematopoietic system to cancer
}

\author{
IŞIL ALBENIZ ${ }^{1}$, ÖZLEM DEMIR-COŞKUN ${ }^{1}$, LEYLA TÜRKER-ŞENER ${ }^{1}$, \\ AYCAN BAȘ ${ }^{1}$, OKTAR ASOĞLU ${ }^{2}$ and RÜSTEM NURTEN ${ }^{1}$
}

Departments of ${ }^{1}$ Biophysics and ${ }^{2}$ Surgery, Istanbul University, Istanbul Faculty of Medicine, 34093 Çapa-Istanbul, Turkey

Received January 18, 2011; Accepted May 6, 2011

DOI: $10.3892 / 01.2011 .315$

\begin{abstract}
Erythrocyte and lymphocyte $\mathrm{NAD}^{+}$glycohydrolase levels were previously found to be elevated in cancer patients. These results were confirmed in an animal model. The administration of live Ehrlich ascites tumor cells to BALB/c mice led to increases in erythrocyte and lymphocyte $\mathrm{NAD}^{+}$glycohydrolase, along with tumor development. Serum samples, ascites fluid from mice with developed tumors, serum samples from cancer patients and Ehrlich cell supernatants had a similar stimulatory effect when administered to mice or when incubated with peripheric lymphocytes in culture. These increases were accompanied by the appearance of an anti-CD38 reactive band of $45 \mathrm{kDa}$ in SDS-PAGE/Western blot analyses of erythrocyte ghost and lymphocyte membrane proteins. The results, supported by flow cytometry data, support previous clinical findings that an enhancement in CD38 expression occurs in the hematopoietic system during proliferative processes. Moreover, they suggest that CD38 expression is triggered at least in part by a certain cytokine(s) secreted by cancer cells. Finally, the results emphasize the prospective use of CD38 expression as a marker of tumor development and progression.
\end{abstract}

\section{Introduction}

$\mathrm{NAD}^{+}$glycohydrolases (EC 3.2.2.5) catalyze the hydrolysis of $\mathrm{NAD}^{+}$into ADP-ribose and nicotinamide. Most eukaryotic $\mathrm{NAD}^{+}$hydrolases are localised at the outer surface of the cell

Correspondence to: Dr Iş1 Albeniz, Department of Biophysics, Istanbul University, Istanbul Faculty of Medicine, 34093 ÇapaIstanbul, Turkey

E-mail: ialbeniz@istanbul.edu.tr

Abbreviations: BCIP, 5-bromo-4-chloro-3'-indolyl phosphate p-tolui-dine; BSA, bovine serum albumin; EATC, Ehrlich ascites tumor cell; EAT, Ehrlich ascites tumor; FITC, fluorescein isothiocynate; FCS, fetal calf serum; CEA, carcinoembryonic antigen; $\mathrm{NBT}$, nitroblue tetrazolium chloride; $\mathrm{NAD}^{+}$, nicotinamide guanine dinucleotide; PBS, phosphate-buffered saline; SDS/PAGE, sodium dodecyl sulfate/polyacrylamide gel electrophoresis

Key words: cancer progression, CD38 expression, cytokine, hematopoietic response, Ehrlich ascites tumor cell, NAD glycohydrolase membrane, and erythrocytes are particularly rich in such ecto$\mathrm{NAD}^{+}$glycohydrolases (1). NAD ${ }^{+}$glycohydrolase and closely associated ADP-ribosyl cyclase activities pertain to a protein that has been identified immunologically as the lymphocyte surface antigen CD38 (2-4) and purified to homogeneity (2). CD38 expression is also widespread beyond the hematopoietic system, with CD38 having been found in different cell systems and tissues (5).

Erythrocyte as well as serum $\mathrm{NAD}^{+}$glycohydrolase and ADP-ribosyl cyclase activities were found to be elevated in cancer, as were the carcinoembryonic antigen (CEA) values $(6,7)$. These results suggested that CD38 expression provides a prognostic outlook on tumor progression, as is the case in monitoring HIV infection and recovery (8).

Subsequently, an animal model was used in this study that would provide additional data to confirm the results obtained with blood samples from cancer patients and to provide insight into the mechanisms underlying these results. To that effect, BALB/c mice to which Ehrlich ascites tumor cells (EATC) were applied by intraperitoneal injections were used as the experimental model. In these mice, the development of ascites was accompanied by a considerable elevation in CD38 expression. A similar effect was achieved by administration of the serum samples from mice with fully-developed tumors or from cancer patients as well as EATC culture medium (EATC supernatant) to normal mice or by their addition to lymphocyte culture. The biological relevance of these results in terms of a response of the organism to cell proliferation processes is discussed, as well as their relationship to tumor- and immune system-generated cytokines.

\section{Materials and methods}

Materials. [Carbonyl- ${ }^{14} \mathrm{C}$ ] $\mathrm{NAD}^{+}$(specific activity $53 \mathrm{Ci} / \mathrm{mol}$ ) was purchased from Amersham International. Chemicals of analytical grade were obtained from Sigma Chemical Co. (St. Louis, MO, USA) and AG-X4 resin from Bio-Rad Laboratories (Hercules, CA, USA). Amerlite CEA-60 assay kit was purchased from Kodak Clinical Diagnostics (Rochester, NY, USA). EATC were obtained from the Research Institute for Experimental Medicine of Istanbul University where the cells had been maintained through successive passages in BALB/c mice over a long period of time. Mouse CD38-specific goat polyclonal IgG, CD-38 (M-19), which was purchased from Santa Cruz Biotechnology (Santa Cruz, CA, USA), was used in the experiments. 
Blood samples were obtained from apparently healthy individuals (controls) and from one of the Tumor Marker Laboratories of the Istanbul Faculty of Medicine. Erythrocytes were purified from anticoagulated blood samples by centrifugation for $20 \mathrm{~min}$ at $3,000 \mathrm{x} \mathrm{g}$ through a Histopaque gradient (Histopaque-1077; Sigma, St. Louis, MO, USA) and resuspended in phosphate-buffered saline (PBS). Erythrocyte numbers were determined after spectroscopic measurements were obtained using calibration curves where $10^{6}$ erythrocytes corresponded to $0.6 \mathrm{~A}_{400}$. Erythrocyte ghosts were prepared as previously described (9). Erythrocytes were briefly suspended in $\mathrm{H}_{2} \mathrm{O}$ and lysed by repeated drawing and pressing of the suspension through the outlet of a micropipette. The lysate was centrifuged for $10 \mathrm{~min}$ at $10,000 \mathrm{x} \mathrm{g}$ and the pellet was washed repeatedly by resuspension and centrifugation in PBS.

Lymphocytes were isolated by layering the blood on a Histopaque gradient and undergoing centrifugation for $30 \mathrm{~min}$ at $400 \mathrm{x} \mathrm{g}$. Interfaced cells were harvested, resuspended in PBS and washed twice in PBS by centrifugation for $10 \mathrm{~min}$ at $3000 \mathrm{x} \mathrm{g}$ in order to separate lymphocytes from thrombocytes (10). The lymphocyte pellet was finally resuspended in PBS. For membrane isolation, the lymphocytes were lysed by 3 freeze/thaw cycles and the supernatants, obtained by centrifugation of lysates for $10 \mathrm{~min}$ at $3000 \mathrm{x} \mathrm{g}$, were used as the lymphocyte membrane fraction (11). The total cell counts were determined on aliquots using a hemocytometer. Cell viability was determined by trypan blue exclusion by mixing one drop of trypan blue with an aliquot of cell suspension and examining the cells under a microscope for dye exclusion (12).

Animal model. EATC $\left(\mathrm{n}=8 \times 10^{5}\right)$ was administered in $0.2 \mathrm{ml}$ $\mathrm{PBS}$ to BALB/c mice by intraperitoneal injections. For each group, four mice were used. Alternatively, $50 \mu \mathrm{l}$ of ascites fluid or serum from mice with developed EAT, serum from cancer patients or EATC supernatant were administered intraperitoneally to new groups of mice. Where indicated, these injections were repeated on day 4. Control groups of mice received PBS, irradiated EATC (50 Gy total dose) or control serum. As an alternative to irradiated EATC, EATC incubated with $1 \mathrm{mM}$ cycloheximide were used, and similar results were obtained. If not otherwise indicated, blood samples were obtained from such mice on every fourth day and subjected to assays as described below.

Lymphocyte culture. Peripheric mouse lymphocytes isolated as described above by centrifugation in Histopaque gradients were cultured in a humidified atmosphere of $5 \% \mathrm{CO}_{2}$ in $2 \mathrm{ml}$ Dulbecco's modified Eagle's medium (DMEM) in 24-well plates at $37^{\circ} \mathrm{C}$ for 7 days. The lymphocytes were supplemented with $10 \%$ fetal calf serum (FCS), serum from normal BALB/c mice, serum from BALB/c mice with developed EAT (Day 8), serum from normal individuals, serum from cancer patients with high CEA values, ascites fluid or EATC supernatant, obtained as described below.

Ehrlich ascites tumor cell culture. EATC were propagated in RPMI-1640, supplemented with $10 \%$ FCS, then with $1 \%$ FCS and finally with serum-free medium with no supplements. EATC culture was maintained in this manner over several passages and for several weeks. The resulting cell culture medium (EATC supernatant) was then assayed either directly or after concentration, using IVSS vivaspin 2 centrifugal concentrator (Sartorius Stedim Biotech, Aubagne, France).

Assayfor $\mathrm{NAD}^{+}$glycohydrolase activity. $\mathrm{NAD}^{+}$glycohydrolase activity in serum samples was determined by separation of [carbonyl- ${ }^{14} \mathrm{C}$ ] nicotinamide released from [carbonyl- ${ }^{14} \mathrm{C}$ ] $\mathrm{NAD}^{+}$on Bio-Rad AG1X4 anion exchange resin (13). Reaction mixtures $(20 \mu \mathrm{l})$ containing $12 \mu \mathrm{l}$ serum, $10 \mathrm{mM}$ $\mathrm{NaCl}, 500 \mu \mathrm{M} \mathrm{ZnCl}$, $50 \mu \mathrm{M} \mathrm{CaCl}_{2}, 20 \mathrm{mM}$ Tris- $\mathrm{HCl}$, $\mathrm{pH} 9.0$ and $5 \mu \mathrm{M}$ [carbonyl- ${ }^{14} \mathrm{C}$ ] $\mathrm{NAD}^{+}$were incubated for $30 \mathrm{~min}$ at $37^{\circ} \mathrm{C}(7)$. Reactions were stopped with $1 \mathrm{ml}$ $0.1 \%$ SDS. The samples were then applied to the Bio-Rad AG1X4 column and [carbonyl- ${ }^{14} \mathrm{C}$ ] nicotinamide was eluted with $\mathrm{H}_{2} \mathrm{O}$. Unhydrolised [carbonyl- ${ }^{14} \mathrm{C}$ ] $\mathrm{NAD}^{+}$was retained on the column and then eluted with $0.5 \mathrm{M} \mathrm{NaCl}$. Radioactivity was determined by counting aliquots from the eluate in a liquid scintillation counter (Packard Tri-Carb 1000 TK, Meriden, CT, USA); counting efficiency for ${ }^{14} \mathrm{C}$ was $90 \%$. Ecto-NAD ${ }^{+}$glycohydrolase activity was assayed in $20 \mu 1$ reaction mixtures containing $5 \times 10^{6}$ erythrocytes (or $5 \times 10^{5}$ lymphocytes) in PBS. After incubation for $30 \mathrm{~min}$ at $37^{\circ} \mathrm{C}$ and subsequent centrifugation of cells, the supernatants were subjected to analysis as above (14).

SDS-PAGE and Western blotting. SDS-PAGE and Western blotting using the CD38-specific goat polyclonal IgG antibody (M-19) were performed as previously described $(15,16)$. The erythrocyte ghost or lymphocyte membrane fractions were solubilised in $1 \mathrm{M}$ Tris- $\mathrm{HCl}, \mathrm{pH} 6.8,2 \%$ glycerin, $10 \%$ SDS, $5 \%$ 2-mercaptoethanol, $0.1 \%$ bromphenol blue, and subjected to SDS-PAGE. The separated proteins were then transferred electrophoretically onto nitrocellulose membranes (Schleicher \& Schuell BioScience, Dassel, Germany). The blots were blocked by $1 \mathrm{~h}$ incubation with $0.5 \%$ BSA in TBST (10 mM Tris- $\mathrm{HCl}, \mathrm{pH} 8.0,150 \mathrm{mM} \mathrm{NaCl}$ and $0.05 \%$ Tween20) followed by successive $1 \mathrm{~h}$ incubations with CD38-specific goat polyclonal IgG (M-19). Detection of immunocomplexes was achieved using alkaline phosphatase-conjugated bovine anti-goat antibody (Sigma) (1:1000 in TBST) and BCIP/NBP as a substrate (7).

The procedure described by the producing company was followed for the determination of CEA.

Flow cytometry. Mouse peripheric lymphocytes $(\mathrm{n}=10,000)$, which were prepared as described above were resuspended in $100 \mu \mathrm{l}$ PBS and incubated with anti-mouse CD38 monoclonal antibody, fluorescein (FITC) conjugated (Cedarlane), at a concentration of $1 \mu \mathrm{g} / \mathrm{ml}$ for $30 \mathrm{~min}$ at $4^{\circ} \mathrm{C}$. Lymphocytes were then washed three times in PBS and analyzed on a FACSCalibur flow cytometer (Becton-Dickinson, San Jose, CA, USA), equipped with a 5-W argon ion laser. FITC excitation occured at $488 \mathrm{~nm}$, and forward and side scatter properties of lymphocytes were used to establish sorting gates. Data acquisition and analysis were carried out using CellQuest Pro software (Becton-Dickinson).

Statistical analysis. Each experiment was repeated at least four times and in each experiment each value was the mean of 4 mice. Statistical analysis was performed according to 
A

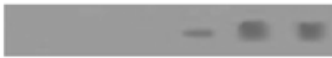

B
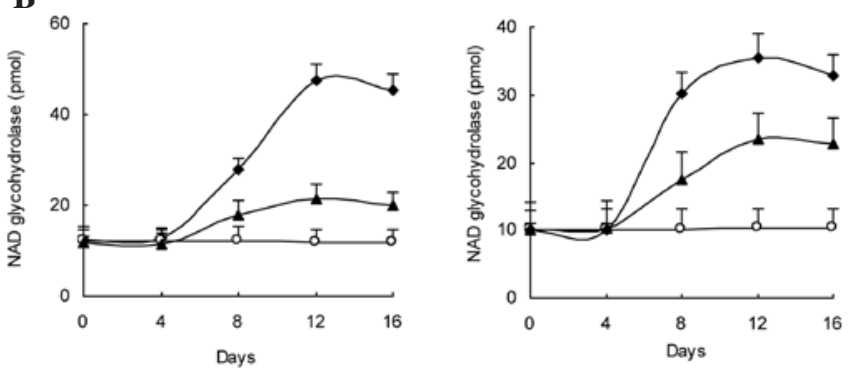

Figure 1. Effect of administration of live EATC to BALB/c mice on CD38expression. (A) Anti-CD38 reactive bands in SDS-PAGE/Western blot analysis of mouse erythrocyte ghost (left panel) and lymphocyte membrane (right panel) proteins. Protein samples (50 $\mu \mathrm{g}$ each) obtained on days 0 (lane 3), 4 (lane 4), 8 (lane 5), 12 (lane 6) and 16 (lane 7) following injection of live EATC were subjected to analysis as described in Materials and methods. Lanes 1 and 2 show samples from untreated BALB/c mice as well as which irradiated EATC were injected, respectively. (B) Increases in erythrocyte (left panel) and lymphocyte (right panel) $\mathrm{NAD}^{+}$glycohydrolase Live $(\bullet-\bullet)$ and irradiated $(\boldsymbol{\Delta}-\mathbf{\Delta})$ Ehrlich cells as well as phosphate-buffered saline (PBS) (0-0) were administered. Experimental details were as described in Materials and methods. Bars are the means \pm SEM. Live EATC z-value $>1.96$ compared with irradiated EATC; live EATC, $z$-value $>3.29$ compared with PBS; irradiated EATC, z-value $>1.96$ compared with PBS Statistical analysis results provided are based on data obtained in NAD glycohydrolase activity tests carried out on day 8 with lymphocytes.

the Kruskal-Wallis ANOVA test and Kruskal-Wallis multiple comparison z-value test.

The investigation was carried out in line with the ethical principles and approval of the Ethics Committee of the Istanbul Faculty of Medicine.

\section{Results}

Effect of administration of live EATC to BALB/c mice on CD38-expression. The objective of this study was to reproduce, in an appropriate animal model, the increases observed in serum and erythrocyte $\mathrm{NAD}^{+}$glycohydrolase in blood samples from cancer patients. To that effect, EATC were administered to $\mathrm{BALB} / \mathrm{c}$ mice by intraperitoneal injections and enzyme activities were then followed up concomitantly to ascites tumor development. In general, a complete image of a developed ascites tumor was observed in these animals in the course of 10-12 days after the injection of EATC. A leukocytosis of 18,000-20,000 (cells/ $\mu \mathrm{l}$ ) appeared to precede the onset of ascites symptoms. It was already detected on day 4 after the application of EATC and remained at this level until the termination of the experiment.

The development of ascites tumors was accompanied by a considerable enhancement in CD38 expression, as revealed by a comparison of anti-CD38 reactive proteins in erythrocyte ghost and lymphocyte membrane fractions in mice with developed ascites tumors versus the controls (Fig. 1A). In line with recent findings of studies pertaining to cancer cases (7), an anti-CD38 reactive protein band of $45 \mathrm{kDa}$ was detected in the Western blot analyses of erythrocyte ghost proteins from mice to which live EATC had been administered. In these mice, the $45 \mathrm{kDa}$ band
A
ERYTHROCYTES

$\begin{array}{lllll}1 & 2 & 3 & 4 & 5\end{array}$

$\mathbf{B}$

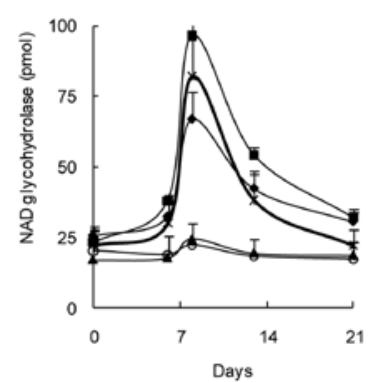

LYMPHOCYTES
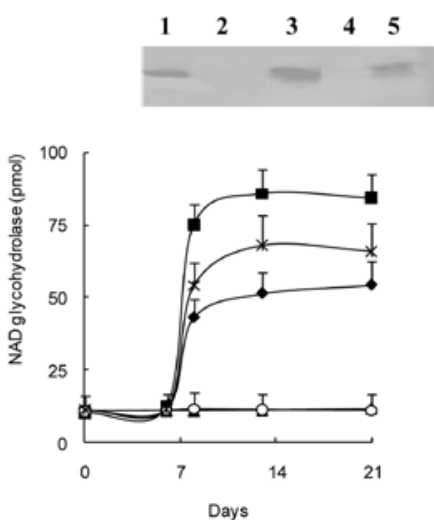

Figure 2. Stimulatory effect of administration of serum and ascites samples from mice with developed EAT and serum from patients with high CEA values to mice on CD38-expression. (A) Anti-CD38 reactive bands in Western blot analyses of mouse erythrocyte ghost (left panel) and lymphocyte membrane (right panel) proteins. Effect of serum and ascites fluid from mice with developed EAT or serum from cancer patients. Administration of the samples $(50 \mu 1)$ to mice was carried out twice with a 4-day interval by intraperitoneal injections. Erythrocyte ghost and lymphocyte membrane proteins $(50 \mu \mathrm{g})$ obtained on day 8 following the injections were subjected to analysis as described in Materials and methods. Lanes 1-5 correspond to samples from mice that received: serum from mice with developed EAT; serum from normal mice (control 1); serum from a patient with a high CEA value; serum from a normal individual (control 2); and ascites fluid. (B) Erythrocyte (left panel) and lymphocyte (right panel) $\mathrm{NAD}^{+}$glycohydrolase in mice that received serum samples from mice with EAT $(\bullet-\downarrow)$; normal BALB/c mice

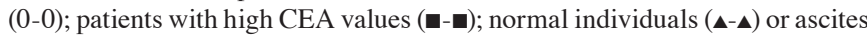
fluid (*_*). Experimental conditions were otherwise as described in Materials and methods. Bars are the means \pm SEM. Serum samples from mice with EATC, $\mathrm{z}$-value $>1.96$ compared with control 1 ; ascites fluid, $\mathrm{z}$-value $>3.29$ compared with control 1; patients with high CEA, z-value >3.29 compared with control 2. Statistical analysis results given are based on data obtained in $\mathrm{NAD}^{+}$glycohydrolase activity tests carried out on day 8 with lymphocytes.

became visible 8 days after the EATC injection and reached a maximum intensity by day 12 after the injection. Western blot analyses of lymphocyte membrane proteins revealed similar results. No anti-CD38 reactive protein band was found in the controls. Western blot analysis findings were supported by the increases observed in erythrocyte and lymphocyte $\mathrm{NAD}^{+}$glycohydrolase (Fig. 1B). Elevations in these activities were observed 8 days after the application of EATC and reached maximum values after 12 days. These values were maintained until day 20 when the experiment was terminated. The increases in erythrocyte and lymphocyte $\mathrm{NAD}^{+}$glyco-hydrolase activities were on average not less than approximately 3-fold higher than the controls. However, in this case, the increases caused by tumor development were 2- to 3-fold higher than the controls.

Stimulatory effect of of serum and ascites samples on CD38expression. The results suggest the existence of certain serum factors as mediators of the stimulatory effect on CD38 expression and related enzymatic activities. Thus, the experiments were repeated with serum and ascites fluid samples from mice with fully developed tumors as well as serum samples from cancer patients. The administration of these samples was carried out twice with a 4-day interval was almost as effective as that of live Ehrlich cells in inducing CD38-expression. As shown in Fig. 2A, the injection of serum and ascites samples 
A

ERYTHROCYTES

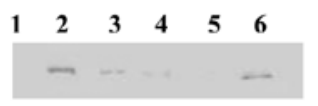

B

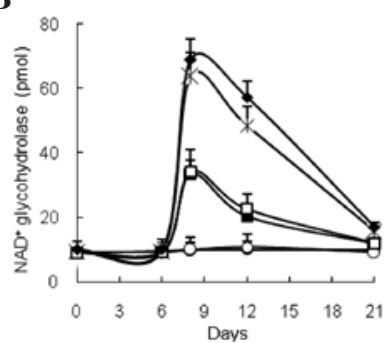

LYMPHOCYTES

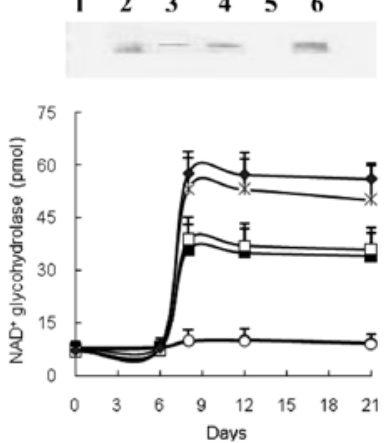

$\begin{array}{llllll}1 & 2 & 3 & 4 & 5 & 6\end{array}$

Figure 3. EATC supernatant alone is capable of inducing CD38 expression. The experimental procedure was, in principle, as described in Fig. 2 with $[1 / 10(\mathrm{v} / \mathrm{v})]$ inclusion of the media obtained after propagation of EATC in culture with or without fetal calf serum (FCS), as additional samples. Protein content of the culture media (EATC supernatant): $1.3 \mathrm{mg} / \mathrm{ml}$ (with FCS) and $0.02 \mathrm{mg} / \mathrm{ml}$ (without FCS). (A) Anti-CD38-reactive bands in Western blot analyses of erythrocyte ghost (left panel) and lymphocyte membrane (right panel) proteins (50 $\mu \mathrm{g}$ applied to SDS-PAGE in each case). Lanes 1-6 correspond to samples from mice which received peritoneal lavement from normal mice as control 1; ascites fluid; EATC supernatant without FCS; EATC supernatant with FCS; serum from normal mice (control 2); and serum from mice with developed EAT. (B) Erythrocyte (left panel) and lymphocyte (right panel) $\mathrm{NAD}^{+}$glycohydrolase activities in mice receiving serum samples from mice with developed EAT $(\bullet-\bullet)$; from normal mice $(0-0)$; ascites fluid $\left(*_{-} *\right)$; peritoneal lavement from normal mice $(\boldsymbol{\Delta}-\mathbf{\Delta})$; EATC supernatant without FCS ( $\square-\square)$ and EATC with FCS (घ-ם). Experimental conditions were otherwise as described in Materials and methods. Bars are the means \pm SEM. Serum samples from mice with EATC, z-value $>3.29$ compared with control 1; serum samples from mice with EATC, z-value $>3.29$ compared with control 2; ascites fluid, z-value >2.93 compared with control 1; EATC supernatant with FCS, z-value $>1.96$ compared with control 1; EATC supernatant without FCS, z-value $>1.96$ compared with control 1. Statistical analysis results given correspond to data obtained in the $\mathrm{NAD}^{+}$glycohydrolase activity tests carried out on day 8 with erythrocytes; similarly for lymphocytes. (C) Forward and side scatter plot of lymphocytes showing the gate RI for flow cytometry. (D-I) Histograms of CD38 expression on mouse peripheric lymphocytes, as analysed by flow cytometry. Lymphocytes from mice receiving serum from mice with developed (D) EAT; (E) from normal mice; (F) ascites fluid; (G) peritoneal lavement with PBS; (H) EATC supernatant without FCS as supplement; (I) EATC supernatant with FCS as supplement and (J) no fluorescein (FITC). Lymphocytes were obtained on day 8 after the administration. Experimental conditions were otherwise as described in Materials and methods.

from mice with developed EATC, as well as serum samples from cancer patients with high ( $>100 \mathrm{ng} / \mathrm{ml})$ CEA values again gave rise to the appearance of the anti-CD38 reactive band of $45 \mathrm{kDa}$ in Western blot analyses of erythrocyte ghost and lymphocyte membrane proteins. The administration of serum samples from control mice and normal individuals failed to exhihibit a similar inducing effect. The serum samples from mice with tumors also gave rise to increases in $\mathrm{NAD}^{+}$glycohydrolase (Fig. 2B). Ascites fluid had a similar and even a higher stimulatory impact. The highest stimulation was achieved with intraperitoneal injections of serum samples from cancer patients. The elevated activity declined gradually in erythrocytes from day 12 to reach control levels by day 20, but activity persisted in the lymphocytes until day 20 .

EATC supernatant alone is capable of inducing CD38 expression. Of note is that the injection of EATC culture
FLOW CYTOMETRY/lymphocytes

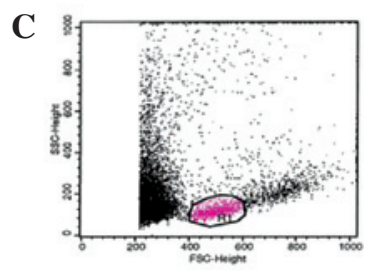

E Control mice serum

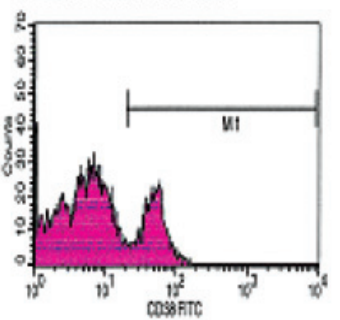

PBS

G

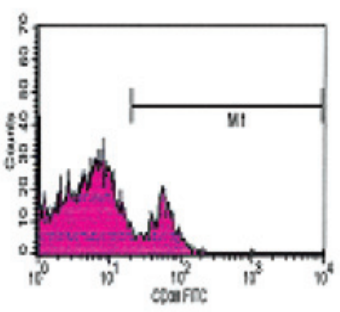

$\mathbf{E A C}(+)$

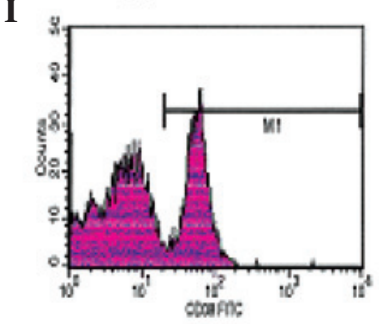

EAT

D
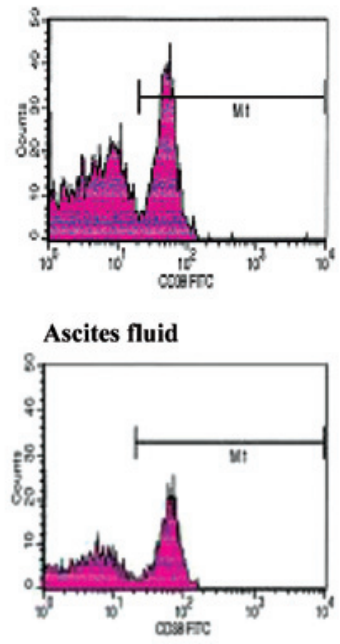

$\mathbf{H}$

EAC(-)

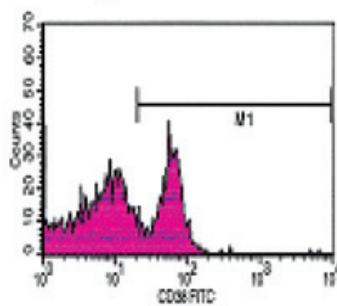

No FITC

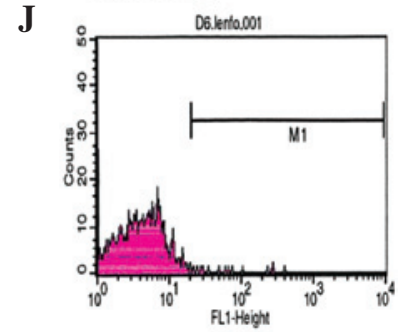

F Ascites fluid

medium propagated either with or without FCS supplement, i.e., EATC supernatant with or without FCS supplement, also resulted in the expression of CD38. In this case, the immunoreactive band, although sharp and distinct, was not as prominent as the bands obtained after injection of serum or ascites fluid samples. However, since this was achieved with trace amounts of protein present in serum-free culture medium, the finding indicated a high level of inducing activity (Fig. 3A). The increase in $\mathrm{NAD}^{+}$glycohydrolase activity promoted by EATC supernatants was also less than that obtained with serum samples or ascites fluid, but significant in comparison to the controls (Fig. 3B). Moreover, the inducing effect on CD38 expression may be shown by flow cytometry (Fig. 3C-J).

CD38 expression in peripheric mouse lymphocytes in culture. Finally, CD38 expression was investigated in a peripheric lymphocyte culture system. The findings obtained in whole mice were reproduced in this system by the addition of serum samples from mice with developed EAT, patients with high CEA values, ascites fluid and, in particular, EATC (Fig. 4). 
A

\section{$\begin{array}{llllll}1 & 2 & 3 & 4 & 5 & 6\end{array}$}

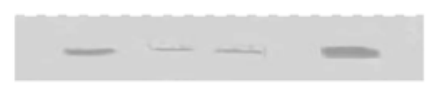

B

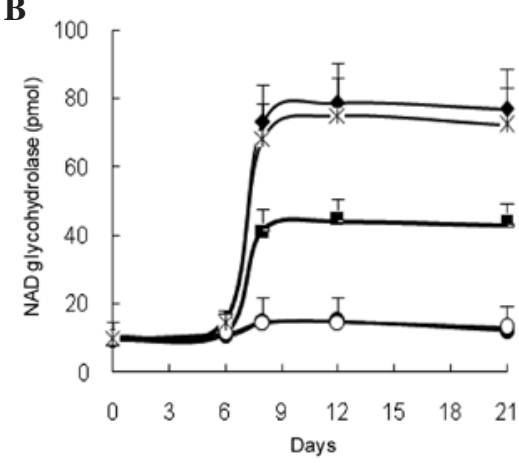

Figure 4. CD38 expression in peripheric mouse lymphocytes in culture Lymphocytes were incubated in RPMI-1640 alone or with supplements as indicated below. On day 8 , the lymphocytes were assayed directly for $\mathrm{NAD}^{+}$ glycohydrolase activity or lysed, and lymphocyte membrane proteins were subjected to Western blot analysis. (A) Anti-CD38-reactive bands in Western blot analyses of membrane proteins from lymphocytes in culture. Lanes 1-6 correspond to lymphocyte samples cultured with peritoneal lavement and supplemented with phosphate-buffered saline (PBS) (control 1); ascites fluid, EATC supernatant with and without fetal calf serum (FCS), serum from normal mice (control 2) and serum from mice with developed EAT. (B) NAD glycohydrolase activity of lymphocytes cultured with serum samples from mice with developed EAT $(\bullet-\bullet)$; from normal mice $(0-0)$; ascites fluid $\left(*_{-} *\right)$;

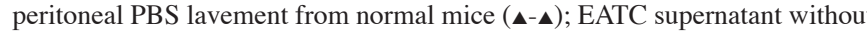
$(\square-\square)$ and with FCS ( $\square-\square)$. Bars are the means \pm SEM. Serum samples from mice with EATC, z-value $>3.29$ compared with control 1; serum samples from mice with EATC, $z$-value $>3.29$ compared with control 2; EATC supernatant without FCS, z-value $>1.96$ compared with control 1 .

\section{Discussion}

Recent investigations have shown that considerable changes in $\mathrm{NAD}^{+} / \mathrm{ADP}$-ribose metabolism (17) and increases in CD38 expression and related enzymatic activities $(6,7)$ occur concomitantly to neoplastic development. CD38 expression has proven to be highly useful in clinics in monitoring HIV-1 infection and recovery (8). Thus, with its pivotal position in lymphocyte activation, CD38 expression appears to be a sensitive and rather specific indicator of immune reaction against variant forms of progressive disease, although its role in this process remains to be clarified. CD38 appears to exert and/or mediate pleiotropic effects through its multifaceted identity as an enzyme, receptor and adhesion molecule.

This study utilized clinical blood samples suggesting the use of an animal model for further and extended studies, and addressed the issue of identifying the primary source of the factors and/or mechanisms that control CD38 up-regulation. The present investigation has been initiated with this consideration in mind, and has used BALB/c mice to which EATC were administered as the experimental model. The results obtained in this conventional system appear to support and extend the data obtained by analyzing blood samples from cancer patients. Thus, increases in CD38 expression and CD38-associated enzymatic activities found in cancer patients were successfully reproduced in mice after the application of live Ehrlich cells, concomitantly with the development of ascites tumors. The increases were also achieved after injec- tions of serum samples from mice with fully developed ascites tumors, cancer patients with high CEA values and ascites fluid. Moreover, the addition of these serum samples resulted in similar increases in CD38 expression and CD38-associated enzymatic activities in peripheric lymphocytes in culture. Thus, CD38 induction was observed both in erythrocytes and lymphocytes in whole animals as well as peripheric lymphocytes in culture. This observation suggests that induction occurs in various hematopoietic cell lineages and at different levels of differentiation.

EATC supernatant exhibited a similar, albeit weaker inducing effect on $\mathrm{CD} 38$ expression. This finding suggests that the observed up-regulation of CD38 is partially triggered by factors originating from the tumor. This effect is likely accompanied and amplified by factors/cytokines produced by the host in response to the tumor. Recent studies provide evidence for the involvement of proinflammatory cytokines in tumor vs. host interactions in cancer disease. Various neoplastic cell lines are known for the production of such proinflammatory cytokines (18-20). Thus, these cytokines are finding increasing use as markers in the detection and prognostic assessment of cancer (21-29). Moreover, cytokines have been shown to enhance CD38 expression in different cell types (26).

The biological relevance of the increases in the reported activities associated with CD38 induction as a response to a proliferative process remains to be clarified. The product of ADP-ribosyl cyclase activity, cyclic ADP-ribose, is a $\mathrm{Ca}^{2+}$-mobilizing second messenger that plays a role in cell differentiation and/or proliferation (27). On the other hand, the ligation of CD38 by selected agonistic monoclonal antibodies is followed via its receptorial properties by signals, resulting in proliferative or apoptotic effects and cytokine induction in various members of the immune system (28). CD38 is also involved in the binding of lymphocytes to endothelial cells via interaction with CD31, its counter-receptor. Finally, CD38 activates, upon ligation with agonistic monoclonal antibody or interaction with $\mathrm{CD} 31$, pathways that lead to the secretion of proinflammatory cytokines from human monocytes (28). Thus, CD38-induction possibly triggered in the course of proliferative processes via certain proinflammatory cytokines may be an event in which proliferative or apoptotic processes are involved, but also with a positive feedback effect on the tumor vs. host reactions.

CD38 expression has gained interest as a prognostic marker in human chronic lymphocytic leukemia (CLL) following the finding that $\mathrm{CD} 38$ expression is associated with the absence of mutations in immunoglobulin variable ( $\mathrm{IgV})$ genes in CLL patients (29). With an increasing percentage of clonal cells expressing CD38, together with ZAP-70 activation as well as absence of mutations in $\mathrm{IgV}$ genes, the prognosis of cases becomes poorer with a shorter survival span and enhanced and repeated requirement for chemotherapy $(5,30)$. CD38 expression appears to reflect the involvement of a key element in the pathogenetic network underlying the disease (5). Through its receptorial properties and/or association with various signal pathways, CD38 protects cells from apoptosis, thereby increasing their survival rate and conferring them increased proliferative potential (5). Thus, CD38 expression appears to have dual implications in the context of leukemia. Firstly, as a key step in the activation of the immune system, it reflects the 
reaction of the host on the ongoing proliferative process. On the other hand, in the particular case of a cancer type originating from the immune system itself, CD38 expression as a survival mechanism for the cancer cell apparently contributes to its proliferative proficiency and malignancy.

\section{Acknowledgements}

This study was supported by the Research Fund of the Istanbul University (project G-147/20082003 and UDP-G/4128). The authors thank Mr. Çağatay Korkut for his data which was useful in the initial stage of the investigation and Mrs. Suzan Adın-Çınar for her help in the flow cytometric analysis. The help of Mr. Halim İşsever in statistical analysis is gratefully acknowledged.

\section{References}

1. Friedman $\mathrm{H}$ and Rapoport SM: Enzymes of the red cell: a critical catalogue. In: Cellular and Molecular Biology of Erythrocytes Yoshikawa H and Rapoport SM (eds). London University Park Press, London, pp181-259, 1974.

2. Zocchi E, Franco L, Guida L, Benatti, U, Bargellesi A, Malavasi F, Lee HC and De Flora A: A single protein immunologically identified as CD38 displays $\mathrm{NAD}^{+}$glycohydrolase ADP-ribosyl cyclase and cyclic ADP-ribose hydrolase activities at the outer surface of human erythrocytes. Biochem Biophys Res Commun 196: 1459-1465, 1993.

3. Howard M, Grimaldi JC, Bazan JF, Lund FE, SantosArgumedo L, Parkhouse RM, Walseth TF and Lee HC: Formation and hydrolysis of cyclic ADP-ribose catalyzed by lymphocyte antigen CD38. Science 262: 1056-1059, 1993.

4. Gelman L, Deterre P, Gouy H, Boumsell L, Debre P and Bismuth G: The lymphocyte surface antigen CD38 acts as a nicotinamide adenine dinucleotide glycohydrolase in human $\mathrm{T}$ lymphocytes. Eur J Immunol 23: 3361-3364, 1993.

5. Deaglio S, Aydin S, Vaisitti T, Bergui L and Malavasi F: CD38 at the junction between prognostic marker and therapeutic target. Trends Mol Med 14: 210-218, 2008.

6. Albeniz I, Demir Ö, Nurten R and Bermek E: NAD glycohydrolase activities and ADP-ribose uptake in erythrocytes from normal subject and cancer patients. Biosci Rep 24: 41-53, 2004.

7. Albeniz I, Demir Ö, Türker-Şener L, Yalçıntepe L, Nurten R and Bermek E: Erythrocyte CD38 as a prognostic marker in cancer. Hematology 12: 409-414, 2007.

8. Liu Z, Cumberland WG, Hultin LE, Prince HE, Detels R and Giorgi JV: Elevated CD38 antigen expression on $\mathrm{CD}^{+} \mathrm{T}$ cells is a stronger marker for the risk of chronic HIV disease progression to AIDS and death in the multicenter AIDS cohort study than $\mathrm{CD}^{+}$cell count, soluble immune activation markers or combinations of HLA-DR and CD38 expression. J Acquir Immune Defic Syndr Hum Retrovirol 16: 83-92, 1997.

9. Dodge JT, Mitchell $\mathrm{C}$ and Hanahan DJ: The preparation and chemical characteristics of the hemoglobin free ghosts of human erythrocytes. Arch Biochem Biophys 100: 119-130, 1963.

10. Böyum A: Separation of leukocytes from blood and bone marrow. Scand J Clin Lab Invest Suppl 97: 7-106, 1968.

11. Liebert M, Ballou B, Taylor RJ, Reiland JM and Hakala TR: A method of membrane preparation for immunoassay. J Immunol Methods 85: 97-104, 1985.

12. Davis LG, Dibner MD and Battey JF (eds): Basic Methods in Molecular Biology, Elsevier Science Publishing Co., Inc., New York, 1986.
13. Kim H, Jacobson EL and Jacobson MK: Synthesis and degradation of cyclic ADP-ribose by NAD glycohydrolase. Science 261: 1330-1333, 1993

14. Yalçıntepe L, Albeniz I, Adın-Çınar S, Tiryaki D, Bermek E, Graeff RM and Lee HC: Nuclear CD38 in retinoic acid-induced HL-60 cells. Exp Cell Res 303: 14-21, 2005.

15. Laemmli UK: Cleavage of structural proteins during the assembly of the head of bacteriophage T4. Nature 227: 680-685, 1970.

16. Gershoni JM and Palade GE: Protein blotting: principles and applications. Anal Biochem 131: 1-15, 1983.

17. Nurten $R$, Üstündağ I, Sayhan $N$ and Bermek E: ADP-ribosylation of human proteins promoted by endogenous NAD glycohydrolase activity. Biochem Biophys Res Commun 200: 450-458, 1994

18. Watson JM, Sensintaffar JL, Berek JS and Martinez-Maza O: Constitutive production of interleukin 6 by ovarian cancer cell lines and by primary ovarian tumor cultures. Cancer Res 50: 6959-6965, 1990

19. Siegall CB, Schwab G, Nordan RP, FitzGerald DJ and Pastan I: Expression of the interleukin 6 receptor and interleukin 6 in prostate carcinoma cells. Cancer Res 50: 7786-7788, 1990.

20. Bendre MS, Margulies AG, Walser B, Akel NS, Bhattacharrya S, Skinner RA, Swain F, Ramani V, Mohammad KS, Wessner LL, Martinez A, Guise TA, Chirgwin JM, Gaddy D and Suva LJ: Tumor-derived interleukin-8 stimulates osteolysis independent of the receptor activator of nuclear factor- kappaB ligand pathway. Cancer Res 65: 11001-11009, 2005.

21. Blay JY, Negrier S, Combaret V, Attali S, Goillot E, Merrouche Y, Mercatello A, Ravault A, Tourani JM and Moskovtchenko JF: Serum level of interleukin 6 as a prognosis factor in metastatic renal cell carcinoma. Cancer Res 15: 3317-3322, 1992.

22. Wittke F, Hoffmann R, Buer J, Dallmann I, Oevermann K, Sel S, Wandert T, Ganser A and Atzpodien J: Interleukin 10 (IL-10): an immunosuppressive factor and independent predictor in patients with metastatic renal cell carcinoma. Br J Cancer 79: 1182-1184, 1999.

23. Michalaki V, Syrigos K, Charles $P$ and Waxman J: Serum levels of IL-6 and TNF-alpha correlate with clinicopathological features and patient survival in patients with prostate cancer. Br J Cancer 90: 2312-2316, 2004.

24. Zhang GJ and Adachi I: Serum interleukin-6 levels correlate to tumor progression and prognosis in metastatic breast carcinoma. Anticancer Res 19: 1427-1432, 1999.

25. Macrì A, Versaci A, Loddo S, Scuderi G, Travagliante M, Trimarchi G, Teti D and Famulari C: Serum levels of interleukin 1beta, interleukin 8 and tumour necrosis factor alpha as markers of gastric cancer. Biomarkers 11: 184-193, 2006.

26. Kang BN, Tirimurugaan KG, Deshpande DA, Amrani Y, Panettieri RA, Walseth TF and Kannan MS: Transcriptional regulation of $\mathrm{CD} 38$ expression by tumor necrosis factor- alpha in human airway smooth cells: role of NF- $\mathrm{BB}$ and sensitivity to glucocorticoids. FASEB J 20: 1000-1002, 2006.

27. Lee HC: Cyclic ADP-ribose: a new member of a super family of signalling cyclic nucleotides. Cell Signal 6: 591-600, 1994.

28. Lande R, Urbani F, Di Carlo B, Sconocchia G, Deaglio S, Funaro A, Malavasi F and Ausiello CM: CD38 ligation plays a direct role in the induction of IL-1beta, IL-6, and IL-10 secretion in resting human monocytes. Cell Immunol 220: 30-38, 2002.

29. Damle RN, Wasil T, Fais F, Ghiotto F, Valetto A, Allen SL, Bunchbinder A, Budman D, D ittmar K, Kolitz J, Lichtman SM, Schulman P, Vincinquerra VP, Rai KR, Ferrarini $M$ and Chiorazzi N: IgV gene mutation status and CD38 expression as novel prognostic indicators in chronic lymphocytic leukemia. Blood 94: 1840-1847, 1999.

30. Matrai Z: CD38 as a prognostic marker in CLL. Hematology 10: 39-46, 2005. 